\title{
Performance of a two Chambers Reactor for the Treatment of an Oily Effluent by Electro flocculation
}

\author{
Thalys de Freitas Fernandes ${ }^{1}$, Gerônimo Barbosa Alexandre², Matheus Albuquerque de \\ Saturno $^{3}$, Ana Paula Trindade Rocha ${ }^{4}$, José Nilton Silva ${ }^{5}$, Gilmar Trindade de Araújo ${ }^{6}$ \\ 1,4,5,6 Federal University of Campina Grande - UFCG, CCT, Campina Grande Campus, Paraíba, Brazil. \\ ${ }^{2,3}$ Federal Institute of Pernambuco - IFPE, EBTT, Garanhuns Campus, Pernambuco, Brazil.
}

Received: 09 Jun 2021; Received in revised form: 07 Jul 2021; Accepted: 14 Jul 2021; Available online: 25 Jul 2021

\begin{abstract}
This work had as objective the development and analysis of a continuum flow reactor and measure its efficiency in the treatment of residual water of the biodiesel purification process using electro flocculation. The reactor was designed with two interconnected chambers with an $0.2 \mathrm{~cm}$ opening between then and reaction volume was $0.883 \mathrm{~L}$ and an electrolytic area of $351 \mathrm{~cm}^{2}$. The electrodes were all aluminum, which were arranged in parallel and with $0.5 \mathrm{~cm}$ spacing, whose power was supplied by a DC source. As design variables, the influence of electrical potential $(U)$ and residence time $(\tau)$ on: current density, final $p H$, removal of oils and greases, COD (Chemical Oxygen Demand), turbidity and total solids, in addition to quantification of the sludge mass obtained and the energy cost of the reactor. The best performance was for a potential of 6.0 volts and a $\tau$ of $29.43 \mathrm{~min}$, with $90 \%$ removal of oils and greases, 53\% COD and $4.38 \mathrm{~g}$ of sludge, culminating in an energy consumption ranging from $0.708 \mathrm{kWhm}^{-3}$ to $4.73 \mathrm{kWhm}^{-3}$. In addition, by visual analysis of the formation of bubbles and the removal of turbidity (94\%), it was concluded that the division of the reactor in two chambers reduced the secondary contamination of the treated effluent.
\end{abstract}

Keywords-electrochemical process, continuous system, effluent treatment, environment.

\section{INTRODUCTION}

The biodiesel production process, for the most part, is based on the use of homogeneous catalysts, usually Sodium Hydroxide $(\mathrm{NaOH})$ or Potassium $(\mathrm{KOH})$ (Lage et al., 2019; Gunaya et al., 2019). In this production route, water is generally used to purify the synthesized biodiesel, which at the end of the process generates a proportion of three liters of wastewater for each liter of synthesized biodiesel (Manique et al., 2012). Therefore, this effluent is alkaline and contains a high content of oils and greases (Chavalparit and Ongwandee, 2009; Meneses et al., 2012).

However, this wastewater contains low concentrations of nitrogen and phosphorus, making an eventual biological treatment, in itself, ineffective (Asia, 2003; Oliveira et al., 2018; Menezes et al., 2017). Other treatment alternatives using only metal salts such as polymers and polyelectrolytes have been used, however, they are expensive, generate excess coagulant materials, and can even lead to secondary pollution (Jun Lu et al., 2015).

Lately, an electrochemical technique has been studied, which although it is still little applied industrially, has aroused a lot of interest due to its simplicity of operation and application in different types of treatment, for example: in textile effluents (Manenti et al., 2014), in waters that show color (Bani-Melhem and Smith, 2012), waters containing pharmaceutical residues (Chou et al., 2011), effluents contaminated with heavy metals (Zhu J et al., 2011), oily effluents (Chavalparit and Ongwandee, 2009; Meneses et al., 2012; Fernandes et al., 2015; Ammar et al., 2019). This is electro flocculation (EF), whose technique is the sum of three sub-processes: coagulation, flotation and electrochemistry (Moussa et al., 2017).

As shown in Fig.1, in an electrochemical reactor containing a set of sacrificial electrodes immersed in the effluent, an electric potential (U) is applied and as a consequence, an electric current is generated in the medium. 
Electronic mobility initially allows oxidation of the anode, releasing the metal $(\mathrm{M})$ in ionic form $\left(\mathrm{Mn}^{+}\right)$. These will then react with hydroxyls $\left(\mathrm{OH}^{-}\right)$generated at the cathode, forming $\mathrm{M}(\mathrm{OH}) \mathrm{n}$, which is the main coagulation agent in the medium, in addition to forming other compounds such as: $\mathrm{M}(\mathrm{OH})^{2+,} \mathrm{M}_{2}(\mathrm{OH})^{24+,} \mathrm{M}(\mathrm{OH})^{2+,} \mathrm{M}(\mathrm{OH})^{4-}, \mathrm{M}_{6}(\mathrm{OH})_{15^{3+}}$ (Holt et al., 2002; Yang Liu et al., 2018). Parallel to coagulation, there is the formation of hydrogen gas $\left(\mathrm{H}_{2}\right)$ at the cathode and oxygen $\left(\mathrm{O}_{2}\right)$ at the anode, which are responsible for the flotation phenomenon, that is, most of the coagulated material that is not decanted, adheres to the bubbles and is carried to the reactor surface (Tezcan Un et al., 2013).

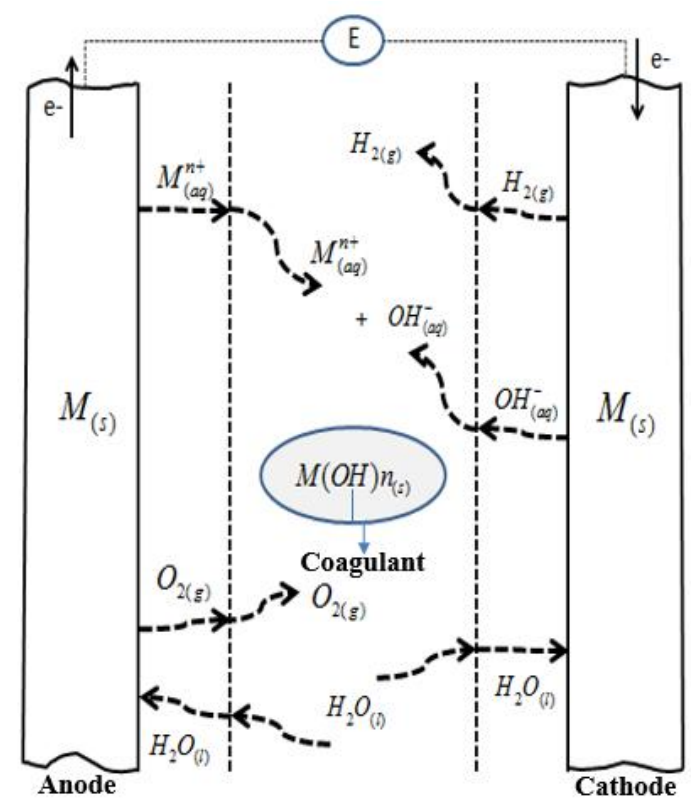

Fig.1: View of the components generated between two sacrificial metal electrodes (M), in the electro flocculation process.

(Designed by the author).

Lately, a lot of work has been done to improve the design of $\mathrm{EF}$ reactors, aiming to improve the efficiency of contaminant removal (Abdelwahab et al., 2009; Chaudhary and Sahu, 2013; Hamdan and El-Naas, 2014; Fernandes et al., 2015; Ammar et al., 2019). With EF experiments, it has been observed that the flotation of particulate material to the reactor surface can be considered a critical step in this process, since the coalescence between bubbles and contaminating particles needs to be effective for the set to reach the top of the reactor (Leite, 2009).

According to II'In and Sedashova (1999), this contact is controlled by hydrodynamic interactions between bubbles and particles, which, in turn, requires intrinsic care with the electric field generated in the medium, with the rate of agitation and with the flow of reactor supply, otherwise the bubbles will burst and contaminate the effluent again (Fig.2).

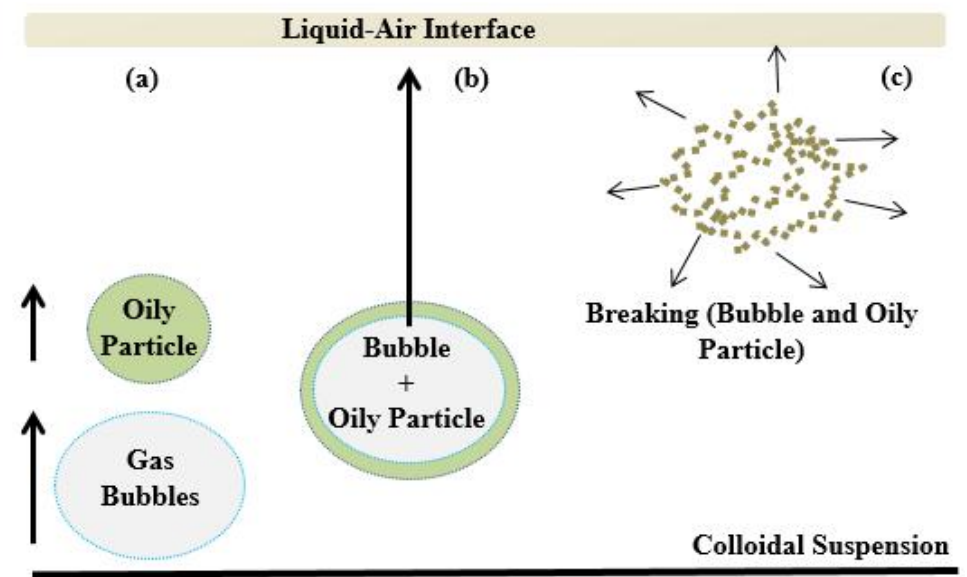

Fig.2: EF flotation process: a) pollutant and $\mathrm{H}_{2}$ and / or $\mathrm{O}_{2}$ gas bubble isolated; b) gas bubble and pollutant adhered and emerging to the surface; c) particles of the pollutant diffusing in the liquid medium after the bubble ruptures. (Designed by the author). 
However, what has been observed is that even with the strict attention given to the control of these parameters, gas bubbles tend to burst naturally, due to the pressure difference that they are subjected to when reaching the reactor's liquid surface. Therefore, in order to minimize the effect caused by the explosion of gas bubbles, this work aimed to develop an electrochemical reactor with continuous flow and consisting of two chambers, to analyze it for efficiency in the treatment of wastewater for the purification of biodiesel.

\section{MATERIALS AND METHODS}

\subsection{Electro flocculation reactor design}

Fig.3 shows the schematic drawing of the EF reactor with the electrodes connected to a direct current source (DC), as well as the numbering of each component, as detailed in the legend. The reactor has the following dimensions: $10 \mathrm{~cm}$ long, $23.5 \mathrm{~cm}$ high and $4.7 \mathrm{~cm}$ wide. The total volume is $1,034 \mathrm{dm}^{3}$ and the reaction volume is 0.883 $\mathrm{dm}^{3}$. There are also two streams, one for feeding and another for the outlet of the treated effluent, in addition to a $25^{\circ}$ inclined gutter at the top, for the drainage of wet sludge, coagulated and flotated material.

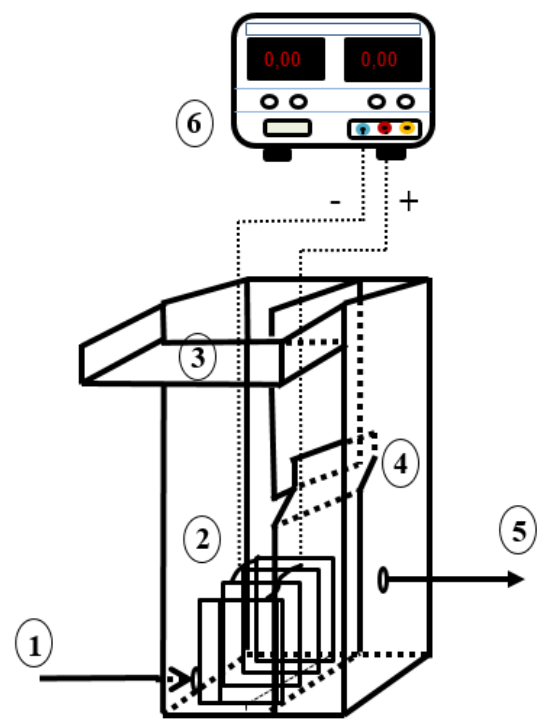

Fig.3: Design of the EF reactor coupled to the DC source: 1-effluent inlet, 2-electrochemical cell chamber, 3-sludge removal channel, 4 - second reactor chamber, 5 - treated effluent outlet, 6 - DC source. (Designed by the author).

The electrochemical cell is composed of four aluminum electrodes whose purity is $96.89 \%$. Each electrode is $0.1 \mathrm{~cm}$ thick and has a total area of $128 \mathrm{~cm}^{2}$. They were distributed alternately, respecting a fixed distance of $0.5 \mathrm{~cm}$ between anodes and cathodes, as studied by Meneses et al., (2012) and Fernandes et al., (2015). The effective reaction area was totaled $351 \mathrm{~cm}^{2}$.

This article can be downloaded from here: www.ijaems.com
The passage of the effluent from the first to the second chamber occurred through an opening of $0.2 \mathrm{~cm}$ located at half the height of the reactor (Fig.4). This idea was supported by the observations made by (Georg et al., 2008). Who affirms that a gas bubble suspended in a viscous medium is basically spherical and follows an upward and rectilinear trajectory, since the upward vertical tensions, drag Force $\left(F_{d}\right)$ and Thrust Force $\left(F_{t}\right)$, which act on the particle (bubble + pollutant), prevail over the gravitational Force $\left(F_{g}\right)$ and horizontal frictional forces $\left(F_{f}\right)$.

Therefore, knowing that the biodiesel effluent has a viscous aspect, it was deduced that most of the particles must emerge in the first chamber of the reactor and that a minority follows a horizontal path towards the second chamber.

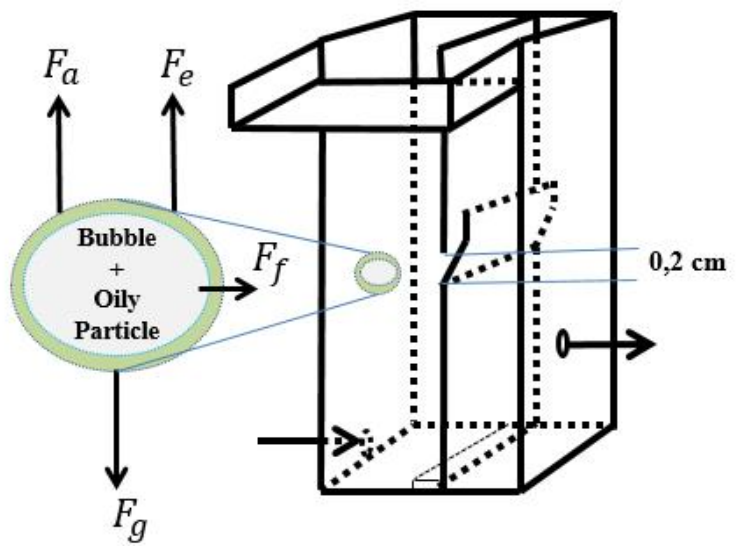

Fig.4: Highlight for the access between the EF reactor chambers and the field of hydrodynamic forces that act on a coagulated particle (contaminant + bubble). (Designed by the author).

\subsection{Analytical Techniques}

The $\mathrm{pH}$ was measured with a bench $\mathrm{pH}$ meter of the brand $\mathrm{pH}$ Meter, model Instrutherm $\mathrm{pH}$ - 1900, with automatic temperature compensation and reading range from 0.0 to 14 and accuracy of 0.01 . The electrical conductivity was measured by direct reading with a TECNOPON conductivity meter, model mCA - 150, with a measurement range between 0.01 and $2000 \mu \mathrm{Scm}^{-1}$ and resolution of $0.1 \mu \mathrm{Scm}^{-1}$. Turbidity was measured with a $\mathrm{HACH}$ turbidimeter, model $2100 \mathrm{P}$, with a scale of 0.0 to 1000 NTU and precision of 0.01 NTU. The concentration of total solids (TS) was determined by the gravimetric method, using a SOLAB oven, model SL 102, with a capacity of $150 \mathrm{~L}$ and automatic programming, whose drying temperature of the samples was $(103 \pm 2){ }^{\circ} \mathrm{C}$. The concentrations of oils and greases $(\mathrm{O} \& \mathrm{G})$ and the chemical oxygen demand (COD) were determined with an Agilent Technologies spectrophotometer; model Cary 60 UV-vis. For COD, samples were previously digested in a 
MARCONI DRY BLOCK MA4004 digesting block, at a temperature of $150^{\circ} \mathrm{C}$ for a period of 2 hours. The oils and greases were previously separated by hexane extraction. All analyzes were adapted from the American Public Health Association (APHA, 2005) and Gobbi (2013).

\subsection{Waste water from biodiesel purification}

The wastewater was obtained synthetically at an ambient temperature of $25^{\circ} \mathrm{C}$. Soybean oil $\left(2.01 \mathrm{gL}^{-1}\right)$, biodiesel $\left(4.01 \mathrm{gL}^{-1}\right)$ and glycerin $\left(1.36 \mathrm{gL}^{-1}\right)$ were inserted in the reactor feed tank, with a capacity of $8.0 \mathrm{~L}$, according to values determined by (Chavalparit and Ongwandee, 2009), for biodiesel wastewater. The mixture was subjected to mechanical stirring at $700 \mathrm{rpm}$, with a Stainless Steel 304 stirrer, model DLMYP2011-100, for a period of $30 \mathrm{~min}$, until an apparently stable emulsion was obtained, with an alkaline $\mathrm{pH}$ ranging between $(9-11)$. The brand soy oil (LISA), $100 \%$ vegetable, was purchased in local stores, while biodiesel and glycerin were synthesized by the transesterification process, via homogeneous catalysis, at the Chemistry and Biomass Laboratory (LQB or CBL) of the Science Center and Technology, UFCG, Brazil. 1M aqueous solutions of $\mathrm{HCl}$ and $\mathrm{NaOH}$, previously prepared, were used to adjust the $\mathrm{pH}$ of the emulsion to 8.0, the $\mathrm{pH}$ of the experiment. According to (Mansoorian et al., 2014; Gatsios et al., 2015; Moussa et al., 2017), for $\mathrm{pH}$ values between 6 and 9 a good formation of coagulating agents in $\mathrm{EF}$ is achieved. Conductivity was measured right after adjusting the $\mathrm{pH}$.

\subsection{Reagents and solutions}

All chemical reagents were of analytical purity grade and were used without pretreatment. The effluent was prepared with local water supply, whose average conductivity was $217 \mu \mathrm{Scm}^{-1}$ and $\mathrm{pH}$ equal to 7 . The solutions used in the physical-chemical analyzes and for $\mathrm{pH}$ control were prepared with pure material, using water distilled with an average conductivity of $1.0 \mu \mathrm{Scm}^{-1}$.

\subsection{Experimental planning}

The performance evaluation of the reactor was carried out with the control over two system factors: Residence Time $(\tau)$ and Electric Potential (U), varying between the levels, low (17.6 min and 3.6 volts) and high (29.43 min and 6.0 volts), as shown in Table 1.

\begin{tabular}{ccc}
\multicolumn{3}{c}{ Table 1: Factors and experimental levels. } \\
\hline Exp. $^{*}$ & $\boldsymbol{\tau}$ & $\mathbf{U}$ \\
\hline & (min) & (volt) \\
\cline { 2 - 3 } 1 & 17.66 & 3.6 \\
2 & 17.66 & 6.0 \\
3 & 29.43 & 3.6 \\
4 & 29.43 & 6.0 \\
\hline
\end{tabular}

*Experiments
The levels were chosen based on studies by (Fernandes et al., 2015), which analyzed an electrochemical reactor with a tubular geometry and aluminum electrodes for treating oily water, yielding removals above $80 \%$ for oils and greases. In this study, the volumetric flow rates of the reactor inlet varied between 0.03 and $0.05 \mathrm{Lmin}^{-1}$. Therefore, for these two extremes, knowing that the proposed reactor useful volume was $0.883 \mathrm{~L}$, the theoretical residence times were calculated (Table 1), using Eq. (1) (Gardiman Junior et al., 2019).

$$
\tau=\frac{V}{v}
$$

Using $\tau$ in (minutes), $\mathrm{V}$ the useful volume of the reactor in (L) and $v$ the volumetric flow of the reactor inlet in (Lmin $\left.{ }^{1}\right)$.

As response variables were analyzed: the density of electric current (DC), the final $\mathrm{pH}$, the concentrations of O\&G, COD, TS, turbidity, in addition to the sludge mass and energy consumption (EC). All were analyzed for behavior over the treatment time, with O\&G, COD, turbidity and TS being analyzed as removal efficiency (\%), calculated from Eq. (2) (Fei Liua et al., 2019).

$$
(\%)=\frac{C_{0}-C_{i}}{C_{0}} \times 100 \%
$$

Adopting $\left(\mathrm{C}_{0}\right)$ the concentration measured at time $\mathrm{t}_{0}=0$ min and $\left(\mathrm{C}_{\mathrm{i}}\right)$ the concentration of the variable analyzed at time $t_{i}$ different from zero.

The behavior of the electric current (I) generated in the reaction medium was also monitored in the DC source, whose values were applied to Eq. (3) to calculate the energy (E) spent with the EF reactor, which was used to calculate energy cost (EC) using Eq. (4).

$$
\begin{aligned}
& E\left(k W h / m^{3}\right)=\frac{U \times I_{m} \times \Delta t}{V_{t}} \\
& E C\left(R \$ / m^{3}\right)=E \times t_{i}
\end{aligned}
$$

$\mathrm{E}$ is given in $\left(\mathrm{R} \$ \mathrm{~m}^{-3}\right), \mathrm{t}_{\mathrm{i}}$ the tariff defined by the energy concessionaire of each state or country given in $\mathrm{R} \$(\mathrm{kWh})^{-1}$, $\mathrm{U}$ the potential difference in (volts), $\mathrm{I}_{\mathrm{m}}$ the average electric current in (A), $V_{t}$ the volume of effluent treated in $\left(\mathrm{m}^{3}\right)$ and $\Delta \mathrm{t}$ the time interval of experiment in $(\mathrm{h})$.

Thus, based on the levels and factors presented, four tests were performed in triplicate, totaling twelve experiments. These were performed at random, according to (Montgomery et al., 2004).

\subsection{The continuous electro flocculation system}

The set of equipment connected to the electrochemical reactor formed the continuous EF system (Fig.5). The tank (T-01) with capacity for $8 \mathrm{~L}$ and a coupled 
agitation system, contained the biodiesel wastewater, which fed the reactor by a peristaltic pump of the brand BPT tube, model KXF-DC-B08. This contained the valve (V-01), which allowed adjusting the flow at the entrance to the reactor (range from 0.003 to $0.08 \mathrm{Lmin}^{-1}$ ). A DC source, which connected to the reactor, allowed adjusting the electrical potential and monitoring the variation of the electrical current throughout the process. At the top of the reactor, the sludge generated during the electrochemical process was removed, which was stored in the tank (T-02) with a capacity of $3 \mathrm{~L}$. In the outlet current for the treated effluent, there was the valve (V-02) used to control the liquid level in the reactor, the value of which remained at 14 $\pm 1.0 \mathrm{~cm}$ throughout the treatment process. The treated effluent was collected in the tank (T-03) and sent to perform the physical-chemical analyzes.

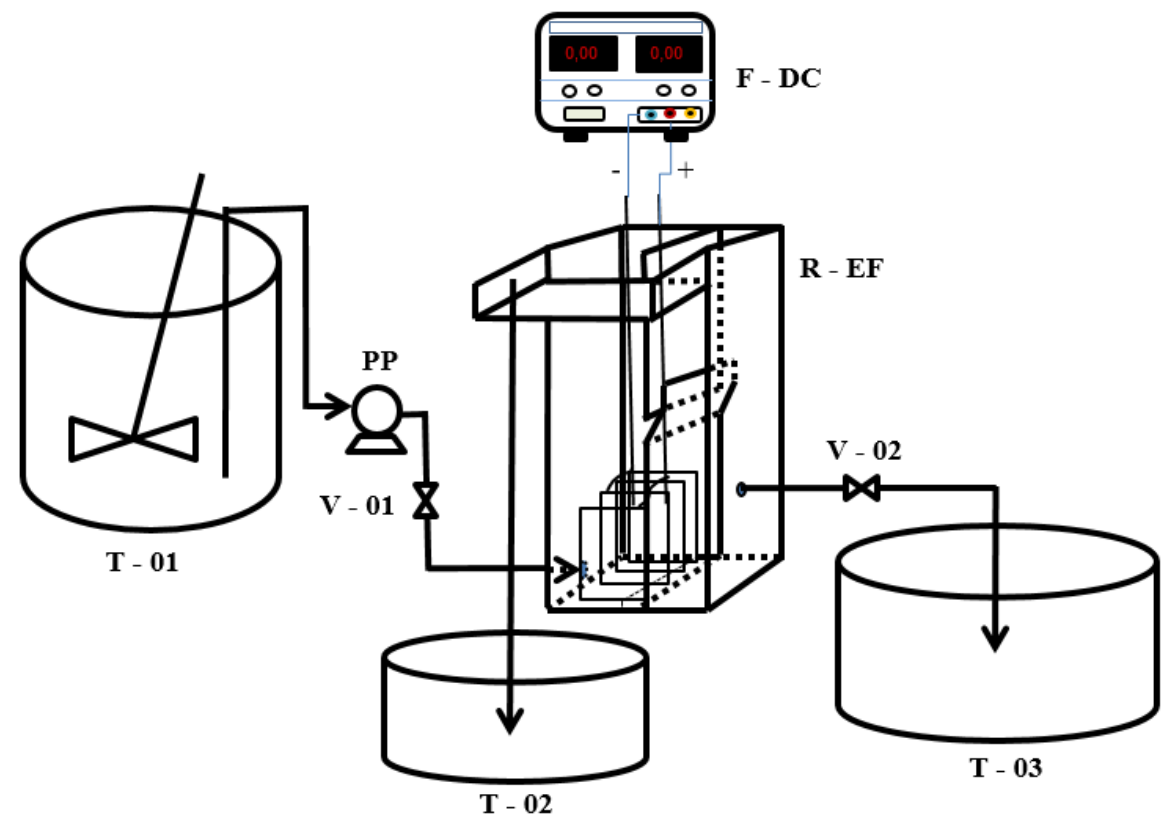

Fig.5: Schematic diagram of the experimental configuration (T-01: biodiesel wastewater tank; PP peristaltic pump; V-01: flow control valve; T-02: sludge tank; R-EF : electro flocculation reactor; F-DC: direct current source; V-02: valve for level control; T-03: tank for the treated effluent). (Designed by the author).

\subsection{Experimental procedure}

The biodiesel wastewater was synthesized in the T-

01 tank, according to the procedure shown in sub-item 2.2. Agitation was reduced from $700 \mathrm{rpm}$ to $100 \mathrm{rpm}$ after preparation and maintained throughout the experiment, to ensure homogenization of the emulsion. A $0.2 \mathrm{~L}$ sample was collected to perform the physical-chemical analyzes at zero time. The peristaltic pump was switched on and the volume flow in the valve (V-01) was adjusted, according to the test $\tau$. When the reactor reached the operating liquid level, the valve (V-02) was manipulated to keep it in the specified range. With the hydrodynamic variables controlled, the DC source was connected to the electrical potential of the experiment and a timer was started. Samples of the treated effluent were collected every $5 \mathrm{~min}$ to perform the physicalchemical analyzes, and so on, until completing $40 \mathrm{~min}$ of the experiment. At the end, the equipment was turned off and the electrodes were washed with soap and water, using steel anchors to ensure the complete scraping of contaminants adhered to the aluminum plates.

\section{RESULTS AND DISCUSSION}

The physical-chemical characterization of the wastewater purification of Biodiesel was performed and listed in Table 2. It was observed that the conductivity, a very important parameter of the process variables presented values because, based on the initial $\mathrm{pH}$ was added a greater or lesser volume of acid and/or alkaline solution to equalize the $\mathrm{pH}$ in 8 , the $\mathrm{pH}$ of the experiments. The initial $\mathrm{pH}$ varied between $(9-11)$, since the biodiesel and glycerin used in the preparation of the effluent were non-pure and came from a homogeneous catalytic process that used potassium hydroxide $(\mathrm{KOH})$ as a catalyst and methyl alcohol as reagent. Therefore, in addition to the high alkalinity resulting from potassium hydroxide, methyl alcohol contributed to the wastewater to present a high quantity and dissolved organic material. 
Table 2: Results of physical-chemical analyzes for wastewater from biodiesel purification.

\begin{tabular}{cc} 
Physical-chemical parameters & Values \\
\hline Initial $\mathrm{pH}$ & $9-11$ \\
Experiment $\mathrm{pH} *$ & 8 \\
Temperature $\left({ }^{\circ} \mathrm{C}\right)$ & $23-25$ \\
Conductivity $\left(\mu \mathrm{Scm}^{-1}\right)$ & $936.7-1198$ \\
Total Solids $\left(\mathrm{gL}^{-1}\right)$ & 1.6317 \\
Chemical Oxygen Demand $\left(\mathrm{mgL}^{-1}\right)$ & 1276.03 \\
Oils and Greases $\left(\mathrm{mgL}^{-1}\right)$ & 1598.1 \\
Turbidity $(\mathrm{NTU})$ & 236.83
\end{tabular}

\section{* Value adjusted with $1 \mathrm{M} \mathrm{HCl}$ and $\mathrm{NaOH}$ solutions. \\ 3.1 Influence of residence time and electrical potential}

The behavior of the electric current density was monitored for each experiment and recorded according to the profiles of (Fig.6). These values were obtained according to (Kobya et al., 2016; Yang Liu et al., 2018), calculating the ratio between the electric current registered in the DC source, over time, by the sum of the reaction area of all electrodes of the electrochemical cell, which is 351 $\mathrm{cm}^{2}$. The initial conductivity for the experiments was 1063 , 1198,1192 and $936.7 \mu \mathrm{Scm}^{-1}$, respectively. According to Moussa et al., (2017), conductivity is essential for the electrochemical processes of wastewater treatment, as it guarantees the conduction of current in the environment and reduces energy consumption.

Exp. (1 and 3) developed on the same average current density, which was approximately $1.6 \mathrm{mAcm}^{-2}$. Therefore, for a voltage of 3.6 volts, $\tau$ did not influence the current density of the experiment. On the other hand, the increase in voltage from 3.6 volts to 6 volts contributed to the increase in the current density of the Exp. (2 and 4) in comparison with the previous ones. This effect derives from Ohm's first law: that the potential (U) is proportional to the electric current (I) in the environment (Walsh, 1993). In addition, according to Faraday's Law, in electrolysis, the electric current is proportional to the amount of metal ions (Al) that are sacrificed at the anode, as can be seen in Eq. (4), (Gamage and Chellam, 2011; Tanneru and Chellam, 2012; Ammar et al., 2019).

$$
m_{A l^{3+}}=\frac{M \times I \times t}{n \times F}
$$

Adopting $\mathrm{m}_{\mathrm{Al}}{ }^{3+}$ is the mass of aluminum ions given off at the anode, $I$ the electric current, $t$ the electrolysis time, $n$ the number of electrons in the redox reaction and $F$ the Faraday constant. Therefore, the greater the applied potential, the greater the current density and, consequently, the greater the number of ions present in the medium, which contribute to sustaining the current at higher values (Priya and Jeyanthi, 2019).

A comparison between Exp. ( 2 and 4$)$ shows that for a voltage of 6 volts, the current density has stabilized at 3.6 and $4 \mathrm{mAcm}^{-2}$, respectively. This shows that the increase in $\tau$ caused a sudden increase in current density, as the consequent reduction in flow decreased the interaction between aluminum cations $\left(\mathrm{Al}^{3+}\right)$ and hydroxy anions $\left(\mathrm{OH}^{-}\right.$ ). This resulted in a medium more saturated in ions than in hydroxy aluminum compounds, contributing to a higher current density value.

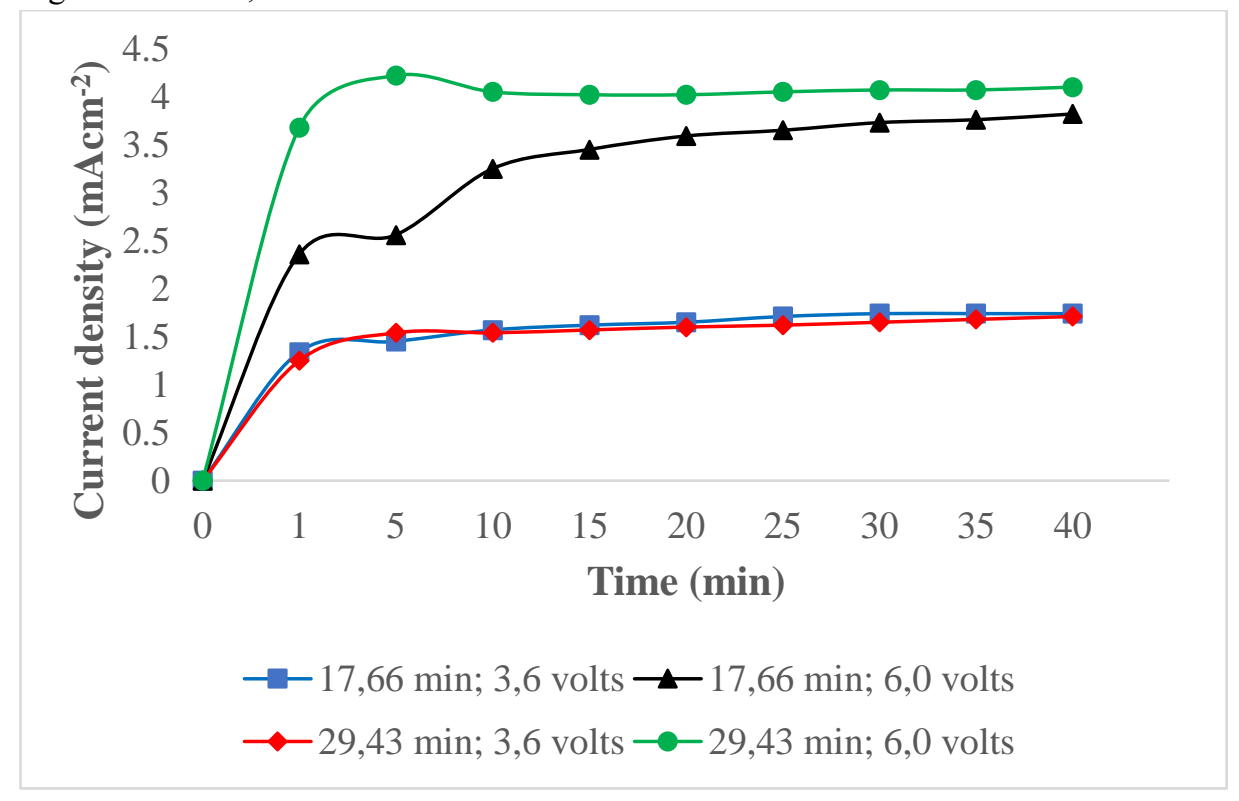

Fig.6: Current density behavior over the treatment time. 
The changes in the $\mathrm{pH}$ behavior over the treatment time were monitored and recorded according to the profiles in (Fig.7), for an initial pH equal to 8. The graphic analysis shows that the $\mathrm{pH}$ decreased for all experiments, stabilizing in the range (6.53 and 7.35), as final pH. Behavior that was also observed by (Meneses et al., 2012; Ammar and Akbar, 2018). With the exception of Exp. (2), the $\mathrm{pH}$ hardly changed between the initial $10 \mathrm{~min}$ and showed a linear trend for all tests in the interval from 0.0 to $25 \mathrm{~min}$ of experiment, from which it became constant until the end of the experiment.

Exp. (1 and 3) showed values approximately equal to 7.0 for the final $\mathrm{pH}$, verifying that for a voltage of 3.6 volts, the $\tau$ variation did not influence the final result. However, when the voltage was increased to 6 volts in Exp.
(2 and 4), there was a small influence of $\tau$ on the final $\mathrm{pH}$. For an initial $\mathrm{pH}$ less than or equal to 8.0 , the increase in voltage caused the reduction of $\mathrm{OH}^{-}$molecules, which gave rise to cationic hydroxide species, such as $\mathrm{Al}(\mathrm{OH})^{2+}$, $\mathrm{Al}(\mathrm{OH})_{2}{ }^{+}, \mathrm{Al}_{2}(\mathrm{OH})_{2}{ }^{4+}, \mathrm{Al}(\mathrm{OH})_{3}$ (Saur et al., 1996; Ammar et al., 2019). However, the formation of these compounds can be more accentuated, if the time that the anionic species $\left(\mathrm{OH}^{-}\right)$meet with the cationic species $\left(\mathrm{Al}^{3+}\right)$ is reduced. This is the case of Exp. (2) when compared to Exp. (4), that is, the reduction in $\tau$, which is due to the increase in the volumetric flow at the reactor inlet, favors greater agitation of the medium. Thus, more hydroxy - aluminum compounds are formed and, consequently, the reduction of free hydroxyls decreases the alkalinity of the medium.

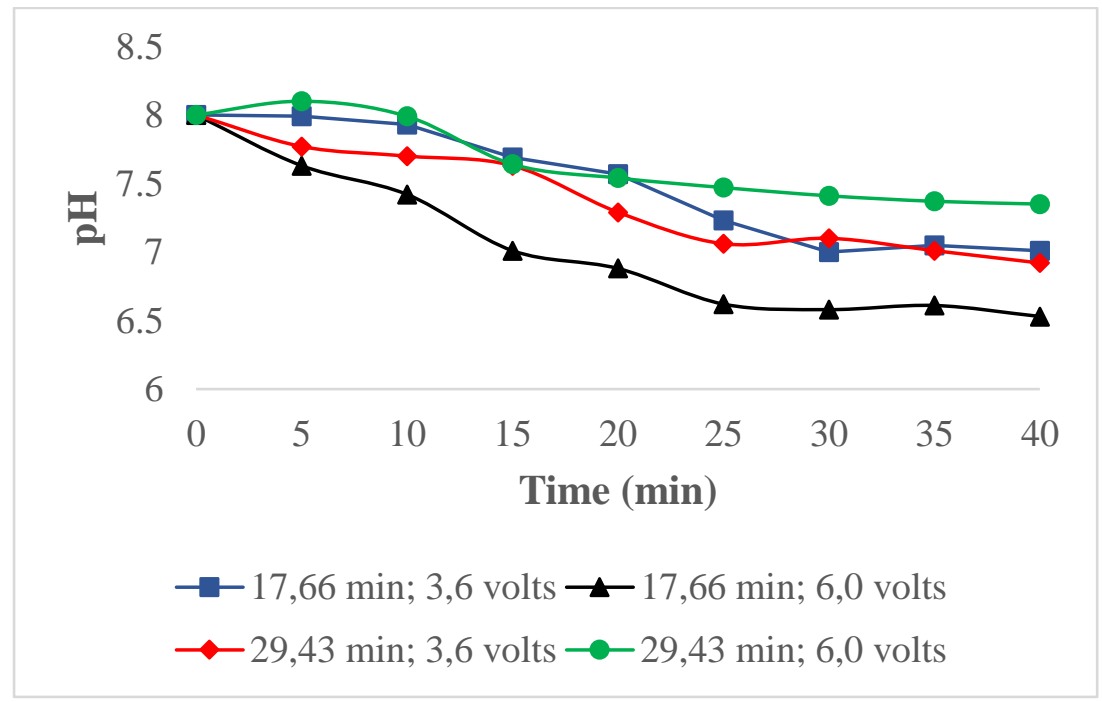

Fig.7: Influence of residence time and electrical potential on the final $\mathrm{pH}$.

In Fig. (8 and 9) the behaviors of the variables, efficiency of removal of O\&G and COD, respectively, are presented. The joint analysis of the profiles shows that for a $\tau$ of $29.43 \mathrm{~min}$ and a potential of 6 volts it is possible to obtain the greatest removals of oils and greases (90\%) and COD (53\%), approximately.

According to (Ammar et al., 2019), for a $\mathrm{pH}$ between 6 and 9, the greater the electrical potential the more insoluble compounds of $\mathrm{Al}(\mathrm{OH})_{3}$ are formed, and the greater the $\tau$, the longer the interaction time between the coagulant with the particles oily, allowing greater removal by coagulation and, consequently, by flotation. In addition, a higher $\tau$ implies a lower volumetric flow at the reactor inlet, therefore, the less force the flow exerts on impurities that are coagulated, minimizing their fragmentation and, therefore, improving the removal of O\&G and COD.
The greater efficiency of O\&G and COD removal contrasted with a higher generation of turbidity and TS. For, for the same experimental conditions, more $\mathrm{Al}(\mathrm{OH})_{3}$ is generated and, consequently, more insoluble material is formed and dispersed in the medium. The profiles of turbidity removal and TS are shown in Fig. (10 and 11), respectively. As noted, the best removals (94\%) and (49\%) were obtained for an electrical potential of 6 volts and an $\tau$ of $17.66 \mathrm{~min}$. That is, for the same amount of $\mathrm{Al}(\mathrm{OH})_{3}$ produced and for the same flotation rate, a shorter interaction time between the impurities and $\mathrm{Al}(\mathrm{OH})_{3}$ results in a lower coagulation rate of oily contaminants. As a consequence, only the micro particles with a larger surface area are removed, mostly, by flotation, as well as $\mathrm{Al}(\mathrm{OH})_{3}$, which is also carried to the liquid surface, resulting in less turbidity and TS. 


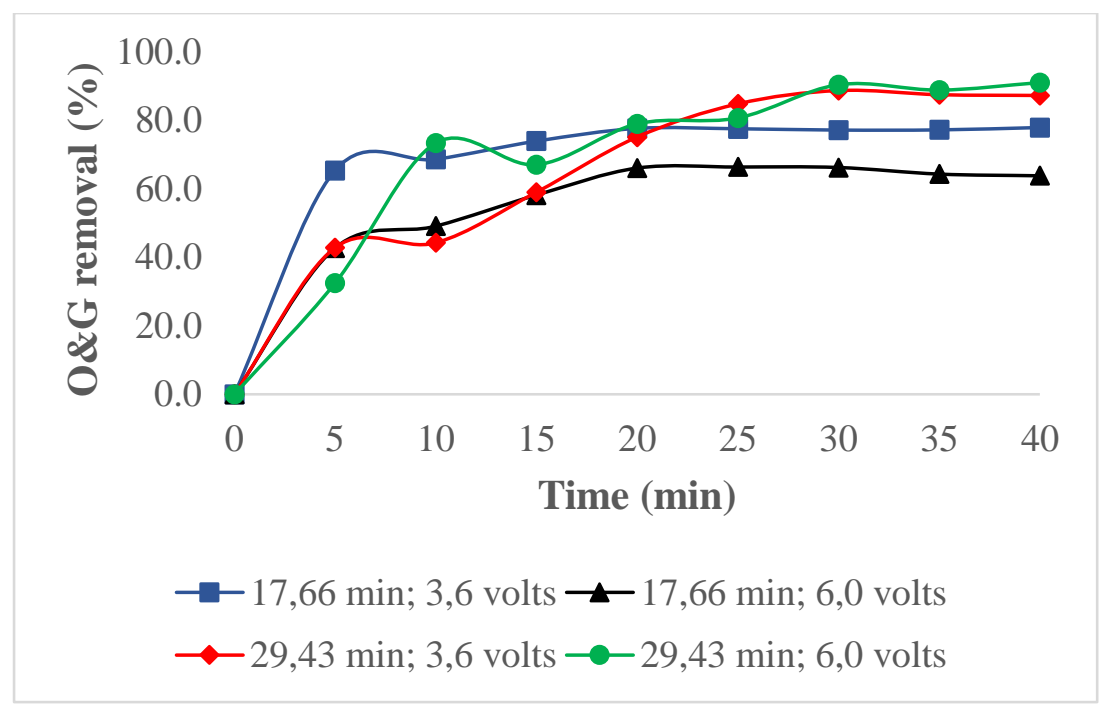

Fig.8: Influence of residence time and electrical potential on the removal of oils and greases.

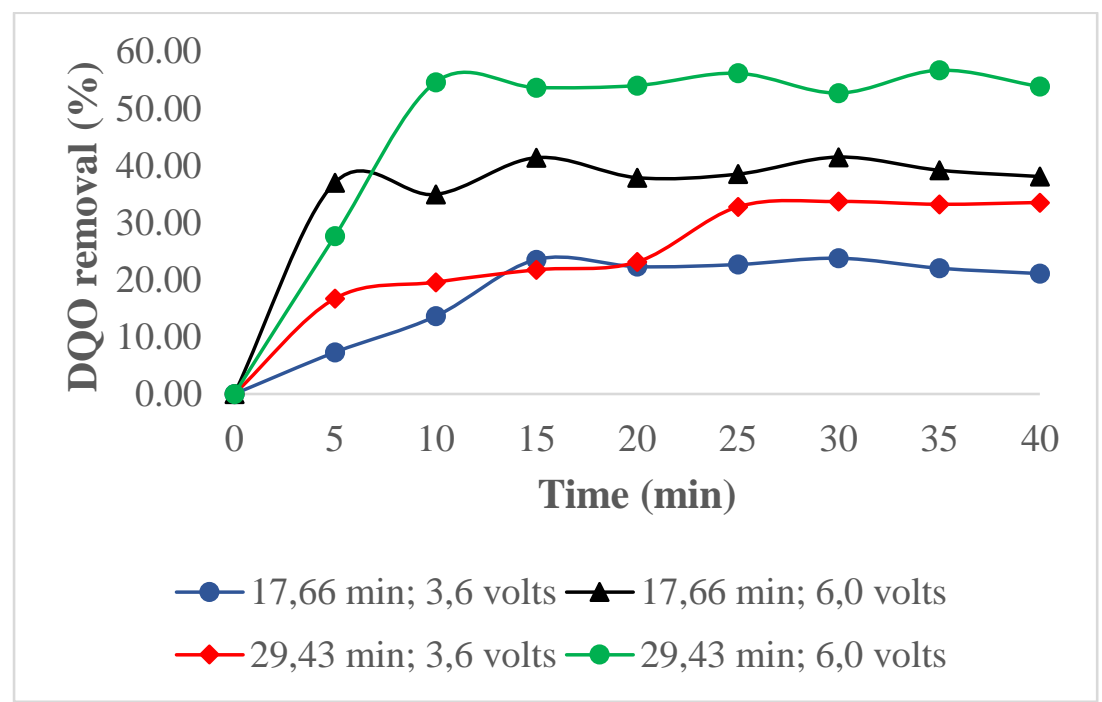

Fig.9: Influence of residence time and electrical potential on COD removal.

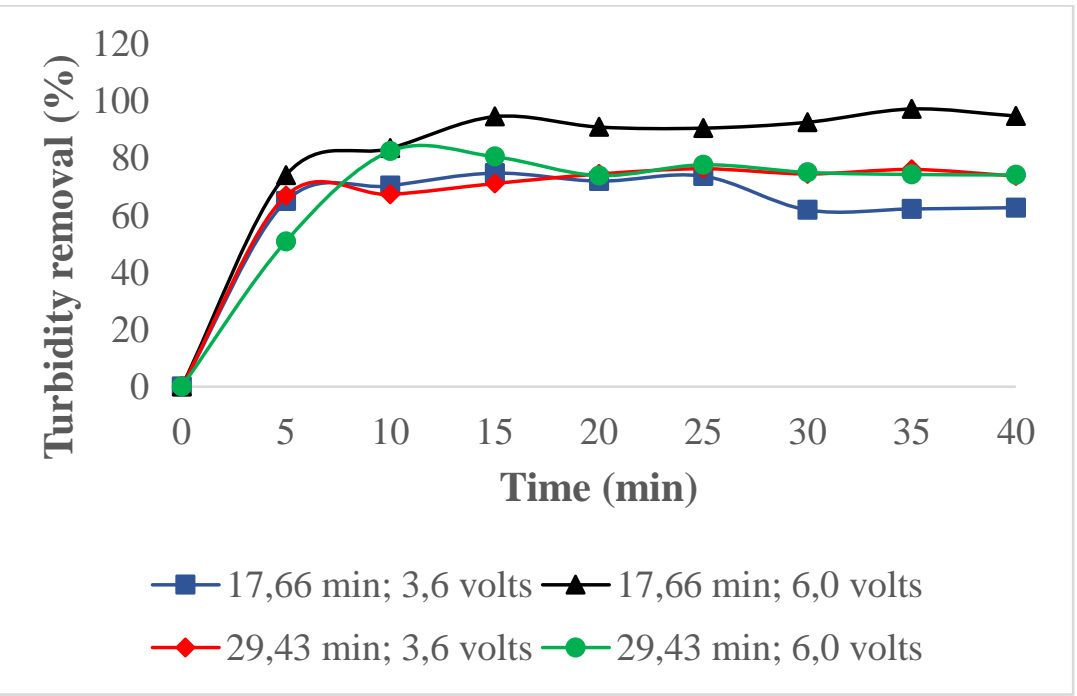

Fig.10: Influence of residence time and electrical potential on the removal of turbidity. 


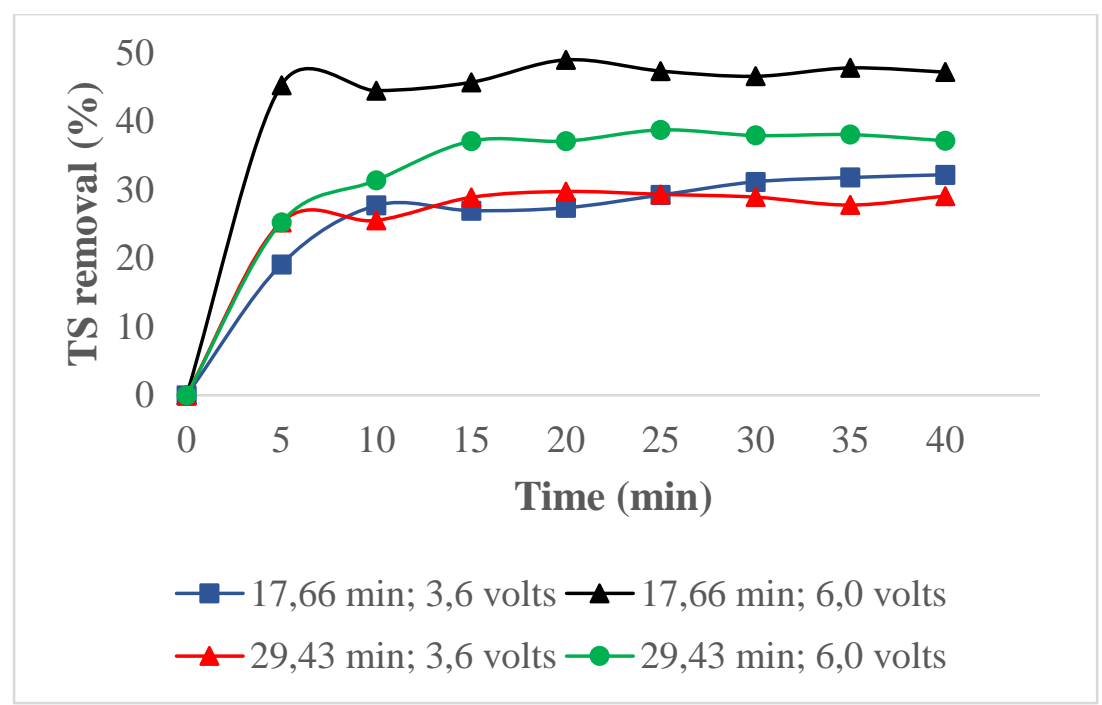

Fig.11: Influence of residence time and electrical potential on the removal of total solids.

The joint analysis on the efficiency of removing $\mathrm{O} \& \mathrm{G}, \mathrm{COD}$, turbidity and TS, allows us to infer that it is in the interval of 0.0 to 10 minutes that the highest rates of removal of impurities from biodiesel wastewater are obtained. In addition, it can be said that the removals become practically constant after the 25 minutes of the experiment. Characteristics that were also observed by (Chavalparit and Ongwandee, 2009; Priya and Jeyanthi, 2019; Ammar et al., 2019).

\subsection{Global analysis of the physical-chemical parameters of the effluent}

Fig. 12 contains the best results for the physicalchemical parameters of biodiesel wastewater after treatment. It is possible to compare the results of the final concentrations of O\&G, COD, TS and turbidity, with the respective initial values for effluent, before treatment, in addition to also comparing them with the limits established by Brazilian legislation (CONAMA, 2011).

As already seen, Exp. (4) presented the best results for O\&G and COD, with removals above $90 \%$ and $53 \%$, respectively. The low COD removal compared to oils and greases is due to the large volume of alcohol used in the synthesis of biodiesel, which cannot be removed by the electro flocculation process (Chavalparit and Ongwandee, 2009). The COD removal efficiency was close to the values obtained by (Siles et al., 2010) and (Chavalparit and Ongwandee, 2009), 45\% and 55\%, respectively. However, with lower O\&G removal efficiency than that obtained by those and by Meneses et al., (2012), for wastewater for the purification of biodiesel. Exp. (2) had the best results for ST and turbidity, with removals above $49 \%$ and $94 \%$, respectively.

The analysis of Fig.12 also shows that the only parameter that meets the Brazilian legislation (CONAMA, 2011) is turbidity. Thus, even though the reactor has a good efficiency in removing $O \& G$ and turbidity, the effluent needs to undergo a post-treatment before being released into the environment, because the high COD values $\left(589.3 \mathrm{mgL}^{-}\right.$ $\left.{ }^{1}\right)$ and $\mathrm{TS}\left(825 \mathrm{mgL}^{-1}\right)$ may favor eutrophication of the water environment (Menezes et al., 2017). A suggestion would be the insertion of the same system in series, or a biological system to reduce COD, or even decantation and/or postreactor PE filtration units to reduce the TS concentration. 


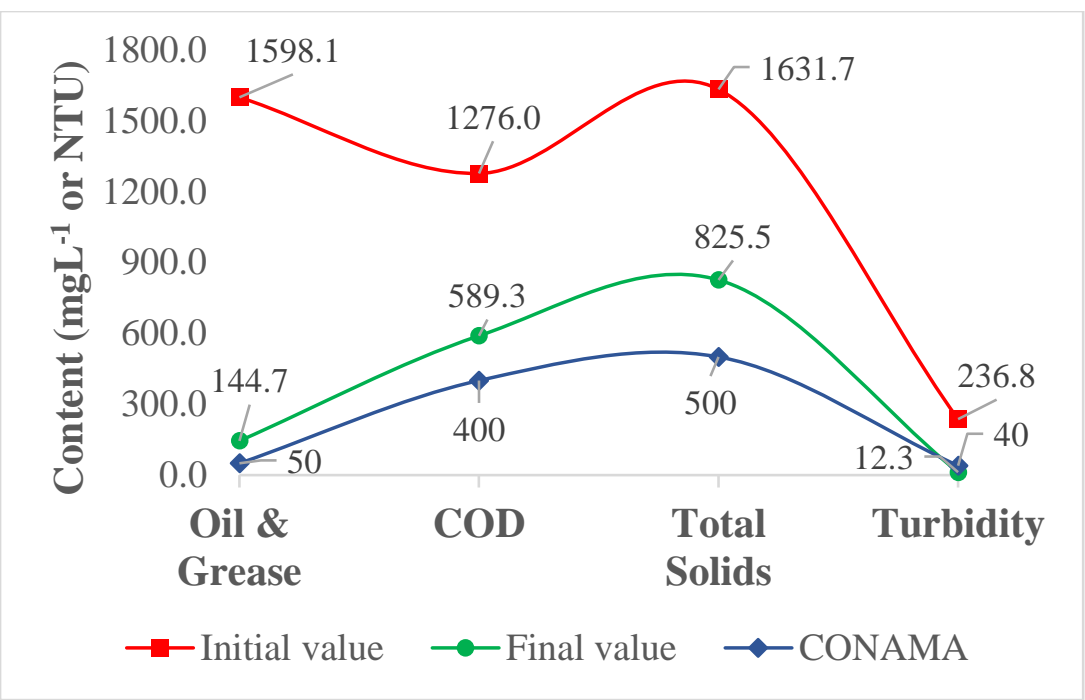

Fig.12: Comparison between the best results obtained for the physical-chemical parameters of wastewater from biodiesel purification.

\subsection{Sludge removal}

Sludge removal is directly related to the flotation of contaminants previously coagulated and flocculated by $\mathrm{Al}(\mathrm{OH})_{3}$ (Kobya et al., 2016). The EF reactor with two chambers was developed with the prerogative that the flotation occurred practically in the region where the electrochemical cell was located. In (Fig.13) the upper image of the reactor is shown, with emphasis on the $\mathrm{H}_{2(\mathrm{~g})}$ and $\mathrm{O}_{2(\mathrm{~g})}$ bubbles, which emerged onto the liquid surface surrounding the coagulated material, called wet sludge. It is possible to notice that the bubbles ascended practically in the first chamber, thus minimizing the contamination of the effluent that flowed into the second chamber of the EF reactor. This statement was ratified by the high removal of turbidity (94\%), since it represents all the insoluble organic and inorganic solids in the medium (APHA, 2005), which were largely removed in the first chamber.

The wet sludge collected by the reactor channel was subsequently dried in the oven and quantified for all tests, the values of which were presented in Fig.14. According to the masses obtained, for a voltage of 3.6 volts and regardless of residence time, practically the same amount of sludge, Exp. (1 and 3), was obtained. On the other hand, with the increase in electrical potential to 6.0 volts, Exp. (2 and 4), the amount of sludge removed was practically doubled. However, this amount is slightly higher for Exp. (4), which operated with a $\tau$ equal to $29.43 \mathrm{~min}$. Therefore, it can be inferred that a greater amount of sludge is obtained at the same time that significant removals of O\&G and COD are achieved.

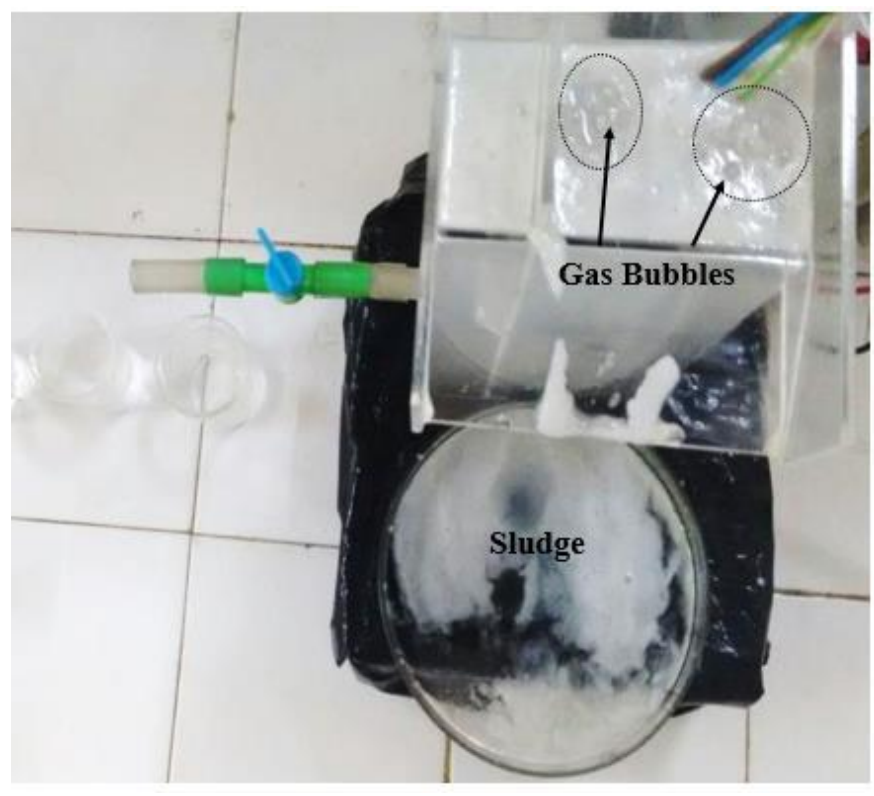

Fig.13: Top view of the electro flocculation reactor used in the treatment of wastewater for the purification of biodiesel after an experiment. (Source: research' image). 


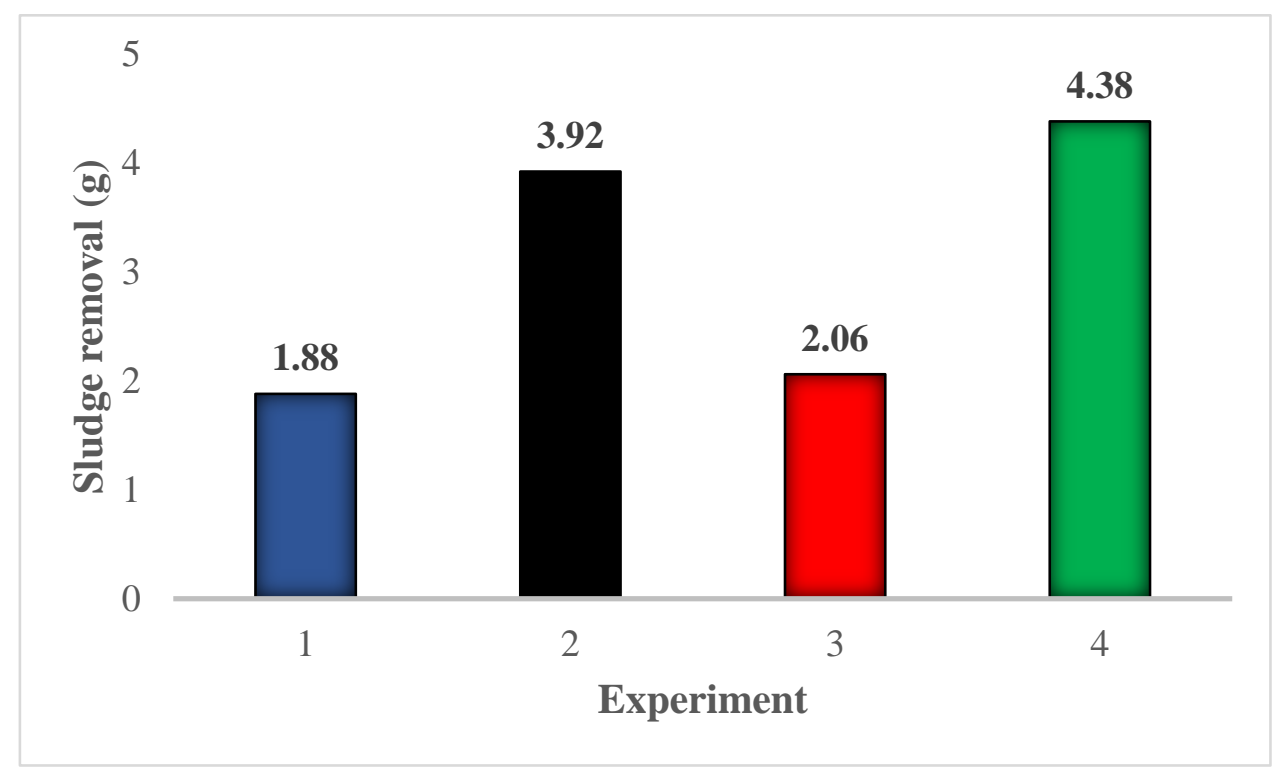

Fig.14: Mass of dry sludge removed in the biodiesel wastewater PE process.

\subsection{The energy consumed by the EF reactor}

The energy (E) spent in the EF reactor for each $\mathrm{m}^{3}$ of treated effluent was calculated using Eq.3 for all experiments, as shown in (Table 3). For this, it was necessary to determine the volume of treated effluent $\left(V_{t}\right)$ and the current mean $\left(I_{m}\right)$, whose selected interval was between 10 and 40 minutes (Fig.6), a period in which the current density values became approximately constant. With the values of $\mathrm{E}$, the energy cost (EC) per $\mathrm{m}^{3}$ of treated effluent was also calculated, multiplying $\mathrm{E}$ by the low voltage industrial tariff, which is $\mathrm{R} \$ 0.49766$ per $\mathrm{kWh}$, according to (ENERGISA, 2020) to the state of Paraiba, Brazil.
The analysis of Table 3 shows that the energy consumption varied between 0.708 and $4.73 \mathrm{kWhm}^{-3}$, which is equivalent to between $\mathrm{R} \$ 0.35$ and $\mathrm{R} \$ 2.36$ per $\mathrm{m}^{3}$ of treated effluent. The highest consumptions occurred in the experiments that obtained the greatest removal of contaminants, that is, Exp. (2 and 4), respectively. Electricity consumption was close to the values found by Chavalparit and Ongwandee (2009); Meneses et al., (2012) and Fernandes et al., (2015), who obtained respectively: $5.57 \mathrm{kWhm}^{-3}, 0.65-2.33 \mathrm{kWhm}^{-3}, 2.07 \mathrm{kWhm}^{-3}$, in the treatment of biodiesel wastewater. Energy costs can be minimized by optimizing this reactor, adding, for example, renewable energy generators, such as photovoltaic or wind systems (Rahmani et al., 2017).

Table 3: Results of the energy spent and the cost obtained with the EF reactor for 40 min of experiment.

\begin{tabular}{ccccccc}
\hline Experiment & $\boldsymbol{\tau}$ & $\mathbf{U}$ & $\mathbf{V}_{\mathbf{t}}$ & $\mathbf{I}_{\mathbf{m}}$ & $\mathbf{E}$ & $\mathbf{E C}$ \\
\hline & $(\mathbf{m i n u t e s})$ & $(\mathbf{v o l t s})$ & $\mathbf{( L )}$ & $\mathbf{( A )}$ & $\left(\mathbf{k W h} . \mathbf{m}^{-3}\right)$ & $\left(\mathbf{R} \mathbf{\$} . \mathbf{m}^{-3}\right)$ \\
\cline { 2 - 7 } 1 & 17,66 & 3,6 & 2 & 0,59 & 0,708 & 0,35 \\
2 & 17,66 & 6 & 2 & 1,27 & 2,54 & 1,26 \\
3 & 29,43 & 3,6 & 1,2 & 0,57 & 1,14 & 0,57 \\
4 & 29,43 & 6 & 1,2 & 1,42 & 4,73 & 2,36 \\
\hline
\end{tabular}

\section{CONCLUSIONS}

The experimental results showed that:

1) the EF reactor reached its best removal efficiency when it was operated with a potential of 6.0 volts and with a $\tau$ of $29.43 \mathrm{~min}$, in which removals above $90 \%$ for oils and greases and $53 \%$ for COD were achieved, in addition to greater sludge removal $(4.38 \mathrm{~g})$. On the other hand, for the same applied potential, when the $\tau$ was reduced to 17.66 min, those removals were reduced and the reactor started to obtain better performance for the removal of turbidity $(94 \%)$ and total solids $(49 \%)$.

2) the electrical potential $(\mathrm{U})$ and the residence time $(\tau)$ are parameters that are intrinsically linked with the greater or lesser formation of the coagulant agent - $\mathrm{Al}(\mathrm{OH})_{3}$ and, therefore, influenced in all the system responses variables.

3) the visualization of gas bubbles on the liquid surface of the first chamber of the reactor and their absence in the second chamber, showed that the section of the EF reactor 
in two compartments was important to minimize the contamination of the treated effluent, which left the reactor through the second chamber, the results of which were confirmed with the removal of more (94\%) of turbidity.

4) the energy spent with the EF reactor proved to be consistent with other values in the literature, which varied between 0.708 and $4.73 \mathrm{kWhm}^{-3}$ of treated effluent, the last value being obtained for its best performance.

5) wastewater from the purification of biodiesel, still needs to undergo a post-treatment before being released into the environment, because it is an effluent with a high COD, originating from glyceric organic matter and a large amount of residual methanol, which could not be removed by electro flocculation.

6) the EF reactor showed significant efficiency for the removal of insoluble solids - oils and greases and turbidity - when used in the treatment of wastewater for the purification of biodiesel. However, it would be interesting to combine it with another treatment system, for example, an activated sludge, chemical coagulation system, or even a physical separation system, such as filters and decanters, to ensure better COD and total solids removal efficiency.

\section{REFERENCES}

[1] Abdelwahab, O., Amin, N.K., El-Ashtoukhy, E.S.Z., 2009. Electrochemical removal of phenol from oil refinery wastewater. J. Hazard. Mater. 163 (2 - 3), 711 - 716.

[2] Ammar, H.S., Akbar, S. A., 2018. Oil field produced water treatment in internal-loop airlift reactor using electrocoagulation/flotation technique. Chinese J. Chem. Eng. 26, 879-885.

[3] Ammar, H.S., Ismail, A.D., Abbas, M. W., 2019. Electrocoagulation technique for refinery wastewater treatment in the internal loop split-plate airlift reactor. Journal of Environmental Chemical Engineering. v.7, n.6, 103489.

[4] APHA. Standard Methods for Examination of Water and Wastewater., 2005. 21th ed. Washington: American Public Health Association.

[5] Asia, U. N. E. a. S. C. f. W., 2003. Wastewater Treatment Technologies: a General Review. Economic and Social Commission for Western Asia, United Nations.

[6] Bani-Melhem, K., Smith, E., 2012. Grey water treatment by a continuous process of an electrocoagulation unit and a submerged membrane bioreactor system. Chemical Engineering Journal. 198 and 199, 201 and 210.

[7] Chavalparit, O., Ongwandee, M., 2009. Optimizing electrocoagulation process for the treatment of biodiesel wastewater using response surface methodology. Journal of Environmental Sciences. v.21, n. 11, p. 1491-1496.

[8] Chaudhary, R., Sahu, O.P., 2013. Treatment of sugar wastewater by electrocoagulation. J. Atmos. Pollut. 1 (1), 5 -7 .
[9] Chou, W.L., Wang, C.T., Huang, K.Y., Liu, T.C., 2011. Electrochemical removal of salicylic acid from aqueous solutions using aluminum electrodes. Desalination. 271, 5561.

[10] CONAMA - National Council for the Environment. RESOLUTION n ${ }^{\circ} 430$, de 13 de March de 2011. Ministry of the Environment. Available in $<$ http://www.mma.gov.br/port/conama $>$ Accessed in 20/05/2020.

[11] ENERGISA. Power Distribution Company in the State of Paraiba. Website: www.energisa.com.br/. Accessed in 20/07/2020.

[12] Fernandes, F. T., Alexandre, B. G., Silva, N. J., Araújo, T. G., 2015. Experimental plant for the treatment of effluent from the production of biodiesel. Scientific Congress of Engineering and Agronomy - CONTECC, v.2, p. 1-4.

[13] Fei L., Zhaoxiang Z., Zenglin W., Xiaqing L., Xiaodong D., Liqiang W., Xuewu W., Zhenhe Y., Jie Z., Mengxin C., Shuo W., 2019. Experimental study on treatment of tertiary oil recovery wastewater by electrocoagulation. Chemical Engineering \& Processing: Process Intensification. 144, 107640.

[14] Gamage, N.P., Chellam, S., 2011. Aluminum electrocoagulation pretreatment reduces fouling during surface water microfiltration, J. Membr, v. 379 (1-2), p. 97105.

[15] Gardiman Junior, B. S., Garcia, G. O., Reis, E. F., 2019. Definition of hydraulic retention time (trh) and efficiency in the treatment of coffee wastewater by an electrolytic system. Virtual Journal of Chemistry. 11 (1), $82-103$.

[16] Gatsios, E., Hahladakis, J.N., Gidarakos, E., 2015. Optimization of electrocoagulation (EC) process for the purification of a real industrial wastewater from toxic metals. J. Environ. Manag. 154, 117-127.

[17] Georg, C.I., Rezende, P.V.R., Maliska, R.C., 2008. Numerical study of the upward flow of a gas bubble in a liquid medium. 1st Brazilian Meeting on Boiling, Condensing and Multiphase Liquid-Gas Flow. Federal University of Santa Catarina (UFSC).

[18] Gobbi, L.R.A., 2013. Treatment of oily water by electroflocculation. Masters dissertation. North of Espirito Santo University Center. Federal University of Espirito Santo (UFES).

[19] Hamdan, S.S., El-Naas, M.H., 2014. An electrocoagulation column (ECC) for groundwater purification. J. Water Process Eng. 4, 25 - 30.

[20] Holt, P.K., Barton, G.W., Wark, M., Mitchell, C.A., 2002. A quantitative comparison between chemical dosing and electrocoagulation. Colloid Surf. A Physicochem. Eng. Asp 211, $233-248$.

[21] Kobya, M., Gengec, E., Demirbas, E., 2016. Operating parameters and costs assessments of a real dyehouse wastewater effluent treated by a continuous electrocoagulation process. Chem. Eng. Process. Process Intensif. 101, 87 - 100.

[22] Jun Lu., Yan Li., Mengxuan Yin., Xiaoyun Ma., Shengling Lin. Removing heavy metal ions with continuous aluminum electrocoagulation: a study on back mixing and utilization 
rate of electro-generated al ions., 2015. Chemical engineering journal, v. 267 , p. $86-92$.

[23] II'In,V.I., Sedashova, O.N., 1999. Industrial ecology - An electroflotation method and plant for removing oil products from effluents. Chemical and Petroleum Engineering. V.35, pp. $07-08$.

[24] Lage, A.H.A., Gonçalves, T.R, Oliveira, A de. U., Saliba, A.W., 2019. Analysis of transesterification and hydrohisterification processes in biodiesel production. Journal of Exact Sciences - JES. 21, 09-14.

[25] Leite, J. C. A. Study of a reactor for electroflotation of wastewater from the oil industry with a view to its reuse., 2009. Doctoral Thesis. Science and Technology Center Process Engineering. Federal University of Campina Grande.

[26] Mansoorian, H.J., Mahvi, A.H., Jafari, A.J., 2014. Removal of lead and zinc from battery industry wastewater using electrocoagulation process: influence of direct and alternating current by using iron and stainless steel rod electrodes. Sep. Purif. Technol. 135, 165-175.

[27] Yang Liu., Jie Yang., Wenming Jiang., Yimei Chen., Chaojiang Yang., Tianyu Wang., Yuxing Li., 2018. Experimental studies on the enhanced performance of lightweight oil recovery using a combined electrocoagulation and magnetic field processes. Chemosphere. 205, 601- 609.

[28] Manenti, D.R., M_odenes, A.N., Soares, P.A., EspinozaQuiñones, F.R., Boaventura, R.A.R., Bergamasco, R., Vilar, V.J.P., 2014. Assessment of a multistage system based on electrocoagulation, solar photo-Fenton and biological oxidation processes for real textile wastewater treatment. Chemical Engineering Journal. 252, 120-130.

[29] Menezes, F.L.G., Silva, A.J.C., Martínez-Huitle, C.A., Zanta, C.L.P.S., Alves, J.J.F., Castro, S.S.L., 2017. Electrochemical treatment of shrimp farming effluent: role of electrocatalytic material. Environ. Sci. Pollut. Res. 24, 6061 e 6070.

[30] Meneses, J.M.; Vasconcelos, R. F., Fernandes, T. F., Araújo, G. T., 2012. Treatment of biodiesel wastewater by electrocoagulation/flotation process: investigation of operational parameters. Química Nova. v. 35, n. 2, p. 235240.

[31] Montgomery, D. C., Runger, G. C., Hubele, N. F., 2004. Statistics Applied to Engineering. Second edition. Rio de Janeiro. LCT Publisher.

[32] Moussa, T. D., El-Naas, H. M., Nasser, M., Al-Marri, J.M., 2017. A comprehensive review of electrocoagulation for water treatment: Potentials and challenges. Journal of Environmental Management. 186, 24-41.

[33] Oliveira, S.M.E., Silva, R.F., Morais, O.C.C., Oliveira, F.B.T., Martínez-Huitle, A.C., Motheo, J.A., Albuquerque, C.C., Castro, L.S.S., 2018. Performance of (in)active anodic for the electro-oxidation of phenolic wastewaters from cashew-nut processing industry. Chemosphere. 201, 740748.

[34] Priya, M., Jeyanthi, J., 2019. Removal of COD, oil and grease from automobile wash water effluent using electrocoagulation technique. Microchemical Journal. 150, 104070 .

[35] Gunaya, E.M., Turkerb, L. E., Tapanc, A. N., 2019. Significant parameters and technological advancements in biodiesel production systems. Fuel. 250, 27 - 41.

[36] Manique, M.C., Faccini, C.S., Onorevoli, B., Benvenutti, E.V., Caramão, E.B., 2012. Rice husk ash as an adsorbent for purifying biodiesel from waste frying oil. Fuel. 92, 56 61.

[37] Rahmani, M., Zerrouki, D., Djafer, L., Ayral, A., 2017. Hydrogen recovery from the photovoltaic electroflocculation-flotation process for harvesting Chlorella pyrenoidosa microalgae. International Journal of hydrogen energy. 30, I-6.

[38] Saur, F.I., Rubach, S., Forde, S. J., Kjaerheim, G., Syverser, U., 1996. Electroflocculation: Removal of oil, heavy metals and organic compounds from oil-in-water emulsions. Filtration \& Separation. $295-301$.

[39] Siles, A. J., Martím, A. M., Chica, F.A., Martín, A., 2010. Aerobic co-digestion of glycerol and wastewater derived from biodiesel manufacturing. Bioresource Tecnology. 101, $6315-6321$.

[40] Tanneru, C.T., Chellam, S., 2012. Mechanisms of virus control during iron electrocoagulation - microfiltration of surface water. Water Res, v. 46 (7), p. $2111-2120$.

[41] Tezcan Un, U., Koparal, A. S., Ogutveren, U. B., 2013. Fluoride removal from water and wastewater with a bach cylindrical electrode using electrocoagulation. Chemical Engineering Journal. v. 223, p. $110-115$.

[42] Vepsalainen, M., 2012. Electrocoagulation in the Treatment of Industrial Waters and Wastewaters. Doctor of Science (Technology). Lappeenranta University of Technology.

[43] Walsh, F.C., 1993. A first course in electrochemical engineering. Electrochemical Engineering Consultancy. England. 381p.

[44] Xu, H.Y., 2016. Investigation of the Optimizing Control Strategy and Dissolution/passivation Mechanism during Electrocoagulation Process for Heavy Metals Wastewater Treatment. $\mathrm{PhD}$ thesis. Environment Science and Engineering. Hunan University.

[45] Zhu J., Wu F., Pan X., Guo J., Wens D., 2011. Removal of antimony from antimony mineflotation wastewater by electrocoagulation with aluminum electrodes. Journal of Environmental Sciences, v. 23, n.7, p. $1066-1071$. 